\title{
Alterações dos cílios em portadores de cavidade anoftálmica
}

\author{
Eyelash alterations in anophthalmicpatients
}

\author{
Silvia Narikawa ${ }^{1}$ \\ Silvana Artioli Schellini ${ }^{2}$ \\ Carlos Roberto Pereira Padovani ${ }^{3}$ \\ Carlos Roberto Padovani ${ }^{4}$
}

\begin{tabular}{|l|}
\hline RESUMO \\
\hline Objetivo: Avaliar a presença de alterações dos cílios em portadores de \\
cavidade anoftálmica. Métodos: Estudo observacional, procurando altera- \\
ções ciliares em portadores de cavidade anoftálmica, atendidos na \\
Faculdade de Medicina de Botucatu. Resultados: Alterações dos cílios \\
foram observadas em 70,7\% dos portadores de cavidade anoftálmica. As \\
alterações mais encontradas foram a ptose dos cílios $(24,4 \%)$, diminuição \\
do número (19,5\%), tricomegalia (19,5\%), triquíase (14,6\%) e entrópio \\
(17,0\%). Conclusão: Os portadores de cavidade anoftálmica possuem \\
alterações ciliares, sendo as mais observadas: ptose de cílios, redução \\
do número, tricomegalia e triquíase. O fator que leva a estas alterações \\
necessita de maiores investigações. \\
\hline
\end{tabular}

Descritores: Cílios/patologia; Anoftalmia; Estudos observacionais
Trabalho realizado na Faculdade de Medicina da Universidade Estadual Paulista "Júlio Mesquita Filho" UNESP - Botucatu (SP) - Brasil.

${ }^{1}$ Residente do Departamento de Oftalmologia, Otorrinolaringologia e Cirurgia de Cabeça e Pescoço da Faculdade de Medicina da Universidade Estadual Paulista "Júlio Mesquita Filho" - UNESP - Botucatu (SP) - Brasil.

${ }^{2}$ Livre- Docente do Departamento de Oftalmologia, Otorrinolaringologia e Cirurgia de Cabeça e Pescoço da Faculdade de Medicina da UNESP - Botucatu (SP) - Brasil.

${ }^{3}$ Pós-Graduando do Departamento de Bioestatística, Instituto de Biociências da Faculdade de Medicina da UNESP - Botucatu (SP) - Brasil.

${ }^{4}$ Professor Titular do Departamento de Bioestatística, Instituto de Biociências da Faculdade de Medicina da UNESP - Botucatu (SP) - Brasil.

Endereço para correspondência: Silvana Artioli Schellini. Departamento de Oftalmologia, Otorrinolaringologia e Cirurgia de Cabeça e Pescoço da Faculdade de Medicina da Universidade Estadual Paulista "Júlio Mesquita Filho" - UNESP - Botucatu (SP) CEP 18618-000 E-mail: sartioli@fmb.unesp.br

Recebido para publicação em 03.04.2006

Última versão recebida em 26.06.2006

Aprovação em 11.07.2006

Nota Editorial: Depois de concluída a análise do artigo sob sigilo editorial e com a anuência do Dr. Marcos Carvalho da Cunha sobre a divulgação de seu nome como revisor, agradecemos sua participação neste processo.

\section{INTRODUÇÃO}

As pálpebras e os movimentos palpebrais fazem parte do mecanismo de proteção dos olhos. Neste sentido, os cílios que são anexos palpebrais também auxiliam no mecanismo de defesa ocular.

Os cílios são pêlos terminais, formados a partir da replicação celular que ocorre dentro do folículo piloso ${ }^{(1-2)}$. A localização habitual dos cílios é a lamela anterior da margem palpebral, onde se encontram fixos obliquamente na pele, anteriormente ao músculo orbicular, podendo atravessá-lo e alcançar o tarso mais profunda e posteriormente ${ }^{(3)}$.

Em relação à margem palpebral, os cílios apresentam crescimento com orientação convexa externa, de modo a se distanciarem do bulbo ocular. A manutenção do posicionamento dos cílios é fruto de vários mecanismos, com forte influência do músculo de Riolan, uma diferenciação do músculo orbicular que circunda os folículos pilosos, mantendo-os em posição ${ }^{(4-5)}$.

Os cílios estão distribuídos em ambas as pálpebras, mas possuem diferenças conforme estejam na superior ou na inferior, ou seja, os cílios das pálpebras superiores são mais longos, mais grossos e mais numerosos e os folículos e bulbos mais profundos e largos, respectivamente quando comparados à pálpebra inferior ${ }^{(2,6)}$.

$\mathrm{O}$ crescimento dos cílios ocorre de maneira cíclica, atravessando as fases de crescimento, atrofia e inatividade (ou anágena, catágena e telógena $)^{(1-2)}$. Durante o ciclo de crescimento ciliar, há folículos em fases diferentes de desenvolvimento e a proporção de folículos que se encontra em cada fase, refletirá a duração relativa desta fase do ciclo. A fase do crescimento é que determina o comprimento final de cada pêlo ou cílio ${ }^{(2)}$.

Quando existem inflamações crônicas, infecções ou queimaduras químicas nas pálpebras, pode haver alterações dos cílios, com redução do número, perda da convexidade e alterações da espessura e da coloração ${ }^{(4-5)}$. 
A transição mucocutânea da margem palpebral pode localizar-se anterior, sobre, ou posteriormente à linha cinzenta. Porém, sua localização mais comum é posterior à linha, freqüentemente no lado conjuntival da margem ${ }^{(7)}$. Esta transição pode estar anormalmente anteriorizada quando há inflamação crônica das pálpebras, quadro conhecido como "conjuntivalização" da margem e que, freqüentemente, relaciona-se também ao direcionamento incorreto dos cílios e a graus variados de entrópio ${ }^{(8)}$.

As alterações dos cílios podem ser divididas da seguinte forma $^{(9)}$ :

\section{A) Quanto ao número:}

Politricose - aumento do número de cílios;

Madarose - perda ou queda de cílios, levando à diminuição do número de cílios na pálpebra.

B) Quanto ao tamanho:

Tricomegalia - crescimento excessivo, acarretando aumento no comprimento final do cílio.

C) Quanto à orientação ou direcionamento:

Triquíase - perda da convexidade externa normal dos cílios;

Ptose ciliar - abaixamento global dos cílios ou de importantes segmentos dos mesmos, devido a atonia da lamela anterior;

Retração ciliar - condição oposta à ptose ciliar, ou seja, aumento da curvatura ciliar devido a retração da lamela anterior;

Cilia incarnata - crescimento do cílio em direção horizontal permanecendo sob a epiderme. Quando aparece sob a conjuntiva tarsal fala-se cilium incarnatum internum.

D) Quanto à pigmentação:

Poliose - perda da melanina ciliar levando à descoloração ou mesmo embranquecimento do cílio.

E) Quanto à espessura:

Afinamento ou espessamento.

F) Quanto ao número de fileiras:

Distiquíase - fileira de cílios anormalmente posicionada atrás da linha cinzenta, nos orifícios das glândulas de Meibomius.

Alterações oculares, assim como o uso crônico de algumas medicações tópicas anti-glaucomatosas, também fazem com que ocorram alterações dos cílios. O uso do latanoprost ou bimatoprost por via tópica mostrou como efeito colateral a tricomegalia e a hipertricose $\mathrm{e}^{(10-11)}$.

Após a cirurgia de enucleação ou evisceração, a anatomia e a fisiologia da órbita sofrem mudanças. Estas mudanças afetam não somente a aparência cosmética do paciente, mas também a função da cavidade ${ }^{(12)}$. Na cavidade anoftálmica é comum ocorrer entrópio, triquíase e ptose dos cílios. Os fatores que podem contribuir com estas anormalidades são a contratura dos fórnices conjuntivais ou tecido cicatricial próximo à margem ciliar ${ }^{(13)}$.

Observações pessoais nos mostraram que indivíduos que perdem o bulbo ocular ou o seu conteúdo apresentam alterações dos cílios e o objetivo deste estudo foi avaliar a freqüência de ocorrência e os quais as alterações dos cílios que existem nos portadores de cavidade anoftálmica.

\section{MÉTODOS}

Este estudo foi retrospectivo, observacional, tendo sido realizado na Faculdade de Medicina de Botucatu - UNESP, São Paulo.

Foram avaliados 41 portadores de cavidade anoftálmica, com o intuito de pesquisar alterações dos cílios. Os indivíduos foram avaliados segundo sexo, tipo de cavidade anoftálmica, causa da perda do olho e presença de alterações localizadas nos cílios.

Os dados foram levantados a partir do arquivo de imagens digitais dos pacientes atendidos no Serviço de Plástica Ocular.

Foram excluídos indivíduos que houvessem utilizado anteriormente ou estivessem em uso de medicações anti-glaucomatosas, do tipo análogos das prostaglandinas.

Os resultados foram submetidos a avaliação estatística pelo método de freqüência de ocorrência para amostras independentes.

\section{RESULTADOS}

Dos pacientes avaliados, a maioria $(63,4 \%)$ era do sexo masculino, com idade menor do que 20 anos (Gráfico 1).

A causa mais freqüente que levou à perda do bulbo ou de seu conteúdo foi o trauma, perfurante ou contuso, com evolução para endoftalmite e phthisis bulbi (Tabela 1).

A distribuição das alterações dos cílios segundo o tipo de cirurgia realizada - evisceração ou enucleação - está apresentada no gráfico 2, onde se pode observar que as alterações

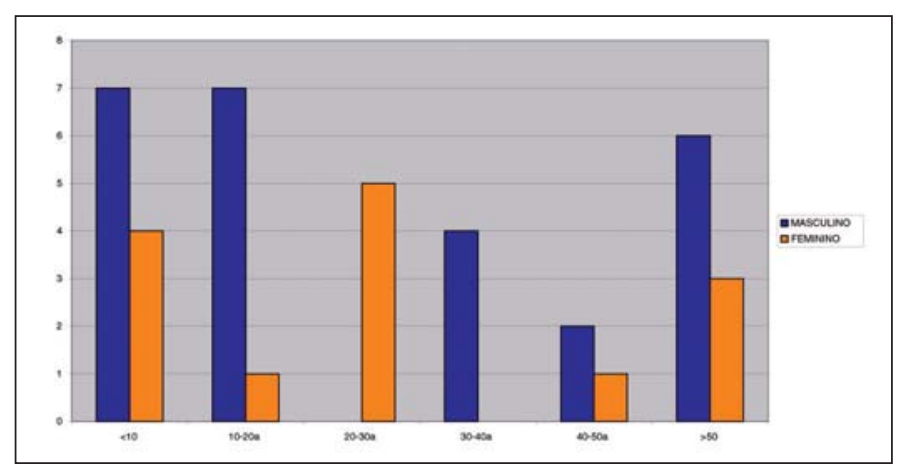

Gráfico 1 - Distribuição dos indivíduos segundo sexo e idade

\begin{tabular}{|c|c|c|}
\hline Causa & № de indivíduos & $\%$ \\
\hline Trauma perfurante & 13 & 32,5 \\
\hline Uveíte/endoftalmite & 8 & 20,0 \\
\hline Phthisis bulbi & 6 & 15,0 \\
\hline Tumor & 5 & 12,5 \\
\hline Glaucoma absoluto & 3 & 7,5 \\
\hline Malformações do bulbo & 3 & 7,5 \\
\hline Trauma contuso & 2 & 5,0 \\
\hline
\end{tabular}




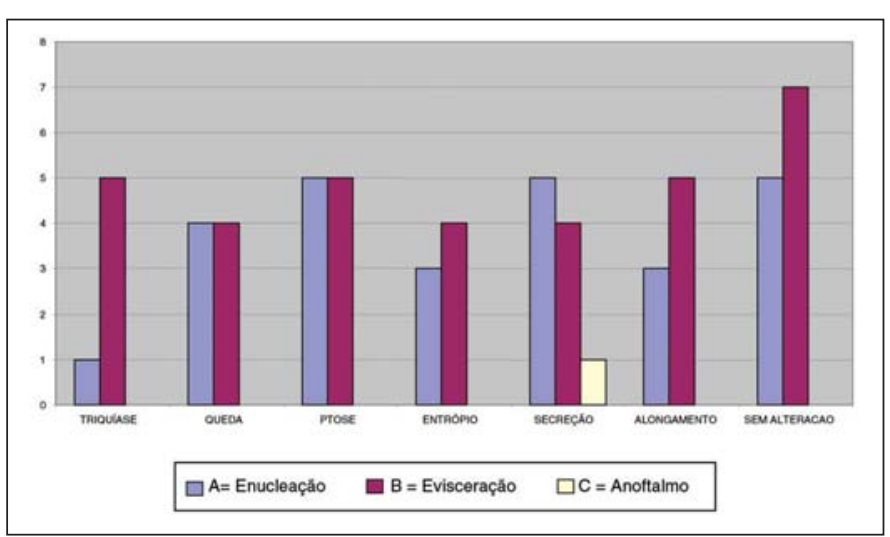

Gráfico 2 - Distribuição das alterações ciliares segundo o tipo de cirurgia realizada

existiram, tanto em cavidades enucleadas, como evisceradas e que $29,3 \%$ das cavidades não apresentaram alterações. Um dos participantes apresentava anoftalmia congênita clínica.

Alguns indivíduos apresentaram mais do que uma alteração dos cílios, estando as mesmas presentes em 70,7\% dos portadores de cavidade anoftálmica. As alterações mais freqüentes foram a ptose dos cílios $(24,4 \%)$, diminuição do número de cílios (19,5\%), tricomegalia (19,5\%), triquíase $(14,6 \%$ ) e alterações que dependem da conformação dos fundos-desaco, como o entrópio $(17,0 \%)$. A presença de secreção nos cílios também foi um achado freqüente, ocorrendo em 21,9\% dos pacientes.

\section{DISCUSSÃO}

Os resultados aqui observados comprovam a hipótese de que as alterações dos cílios são freqüentes nos portadores de cavidade anoftálmica.

As observações de que o sexo masculino e menores do que 20 anos foram observados com maior freqüência diz respeito ao perfil dos portadores de cavidade anoftálmica, em geral, jovens e homens. O mesmo se pode dizer da causa da perda do bulbo, tendo sido encontrado o trauma como a maior causa de perda do bulbo ocular.

O tipo de cirurgia realizada não interfere na possibilidade de se ter alterações dos cílios, estando elas presentes, tanto em cavidades enucleadas, como evisceradas.

O tempo de uso da prótese externa e o modo de utilização poderiam estar implicados na existência de alterações dos cílios. Porém, este ponto não foi abordado neste estudo, ficando a sugestão para estudos futuros.

O fator etiológico para a existência das alterações dos cílios poderia ser o fato das pálpebras não possuírem com a prótese externa o mesmo contato que possuem com o bulbo ocular, resultando em estase de secreções nas glândulas que se localizam nas pálpebras e conseqüente inflamação e/ou infecção. Outro ponto a se considerar seria o fato da prótese externa provocar trauma constante para as estruturas palpebrais. E ainda, manipulação excessiva da prótese poderia provocar alterações palpebrais, dentre elas as que ocorrem nos cílios.

Embora a prótese ocular seja, quase sempre, confeccionada a partir de um molde da cavidade, algum tipo de espaço vazio é observado entre a superfície posterior da mesma e a cavidade. Secreção lacrimal, muco e resíduos, estagnados neste espaço, constituem um meio de cultura para o crescimento bacteriano, determinando uma conjuntivite superficial crônica que parece ser a principal causa da secreção acumulada na cavidade, pálpebras e cílios ${ }^{(14)}$.

Desta forma, a constatação de que os portadores de cavidade anoftálmica possuem mais freqüentemente meibomite poderia confirmar a nossa hipótese.

Para firmar esta hipótese também há necessidade de se comparar estes achados com outro grupo de pessoas, pareado por idade e sexo e que possuam os olhos saudáveis.

Portanto, as alterações ciliares são freqüentes em portadores de cavidade anoftálmica, havendo necessidade de novos estudos para confirmar que é a inflamação crônica o fator etiológico que leva a estas alterações.

\section{CONCLUSÃO}

Os portadores de cavidade anoftálmica possuem alterações ciliares, sendo as mais observadas: ptose de cílios, redução do número, tricomegalia e triquíase. O fator que leva a estas alterações necessita de maiores investigações.

\section{ABSTRACT}

Purpose: To evaluate the eyelash alterations in anophthalmic cavity patients. Methods: An observational study was done looking for eyelash alterations in anophthalmic cavity patients at "Faculdade de Medicina de Botucatu". Results: Eyelash alterations were observed in $70.7 \%$ of the anophthalmic patients. The most frequently observed eyelash alterations were eyelash ptosis $(24.4 \%)$, reduction in the quantity $(19.5 \%)$, trichomegaly (19.5\%), trichiasis (14.6\%) and entropium $(17.0 \%)$. Conclusion: The anophthalmic cavity patients have eyelash alteration and ptosis, reduction in quantity, trichomegaly, trichiasis are the most common observed situations. Further studies are needed to know more about it.

Keywords: Cilia/pathology; Anophthalmos; Observational studies

\section{REFERÊNCIAS}

1. McKee PH. Normal histology of the skin. In: McKee PH. Pathology of the skin. 2nd ed. London: Mosby-Wolfe; 1996. v.1. p.1-32.

2. Elder MJ. Anatomy and physiology of eyelash follicles: relevance to lash ablation procedures. Ophthal Plast Reconstr Surg. 1997;13(1):21-5. 
3. Bron AJ, Tripathi RC, Tripathi BJ. The ocular appendages: eyelids, conjunctiva and lacrimal apparatus. In: Bron AJ, Tripathi RC, Tripathi BJ. Wolff's anatomy of the eye and orbit. 8th ed. London; New York: Chapman \& Hall Medical; 1997. v.1. p.30-84.

4. Schellini SA. Triquíase e distiquíase. In: Matayoshi S, Forno EA, Moura EM. Manual de cirurgia plástica ocular. São Paulo: Roca; 2003. p.51-4.

5. Araújo FAM. Patologia ciliar no Hospital das Clínicas da Faculdade de Medicina de Ribeirão Preto - USP [tese]. Ribeirão Preto: Faculdade de Medicina da Universidade de São Paulo; 2001.

6. Gonnering RS. Eyelid anatomy. In: Stephenson CM, editor Ophthalmic plastic, reconstructive, and orbital surgery. Boston: Butterworth-Heinemann; c1997. v.1. p.71-82.

7. Wulc AE, Dryden RM, Khatchaturian T. Where is the gray line? Arch Ophthalmol. 1987;105(8):1092-8.
8. Kersten RC, Kleiner FP, Kulvin DR. Tarsotomy for the treatment of cicatricial entropion with trichiasis. Arch Ophthalmol. 1992;110(5):714-7.

9. Duke-Elder S, MacFaul PA. Disorders of the eyebrows and lashes. In: Duke-Elder S. System of ophthalmology. London: Henry Kimpton; 1974. v.13. p.373-90.

10. Sugimoto M, Sugimoto M, Uji Y. Quantitative analysis of eyelash lengthening following topical latanoprost therapy. Can J Ophthalmol. 2002;37(6):342-5.

11. Herane MI, Urbina F. Acquired trichomegaly of the eyelashes and hypertrichosis induced by bimatoprost. J Eur Acad Dermatol Venereol. 2004;18(5):644-5.

12. Soll DB. The anophthalmic socket. Ophthalmology. 1982;89(5):407-23.

13. Orbit, eyelids, and lacrimal system: 2001-2002. American Academy of Ophthalmology; 2001. p.107-15.

14. Neves ACC, Rode R, Rode SM, Jorge AOC. Avaliação clínica e microbiológica da secreção conjuntival em usuários de prótese ocular em resina acrílica. Rev Biociências. 2001;7(2):43-9.

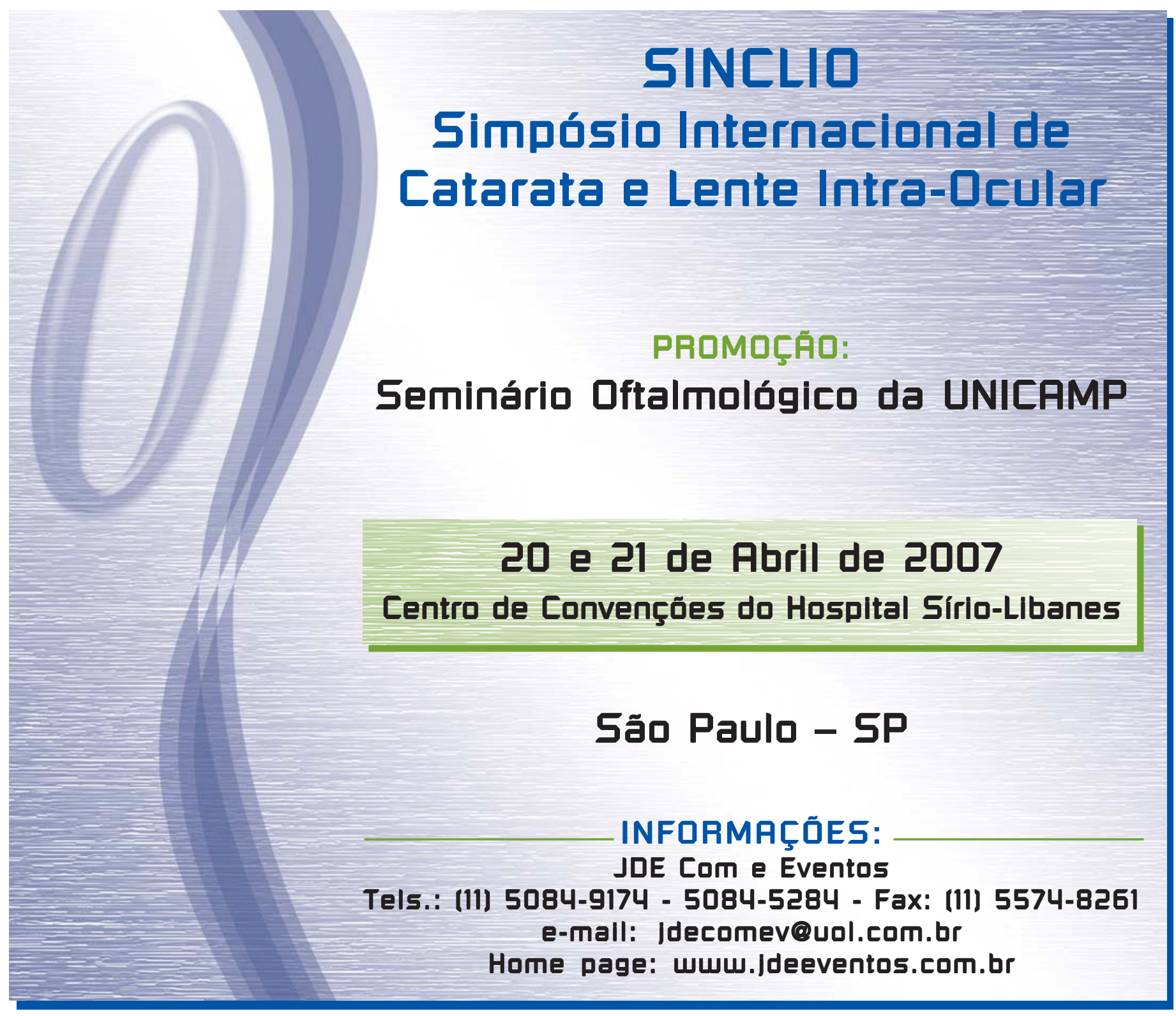

